\title{
Sincronização de estro com CIDR reutilizado em cabras lactantes da raça Toggenburg tratadas com somatotropina bovina recombinante (r-bST)
}

\author{
[Estrous synchronization with recycled CIDR in lactating Toggenburg does treated with \\ recombinant bovine somatotropin $(r-b S T)]$ \\ E.A.M. Amorim ${ }^{1}$, C.A.A. Torres ${ }^{2}$, J.F. Fonseca ${ }^{3}$, L.S. Amorim ${ }^{1}$, V.V. Maffili ${ }^{4}$, J.H. Bruschi ${ }^{5}$, \\ J.D. Guimarães ${ }^{6}$, P.R. Cecon ${ }^{7}$, N.G. Alves ${ }^{8}$ \\ ${ }^{1}$ Aluno de pós-graduação - UFV - Viçosa, MG \\ ${ }^{2}$ Departamento de Zootecnia - UFV - Viçosa, MG \\ ${ }^{3}$ Embrapa Caprinos - Sobral, CE \\ ${ }^{4}$ FIOCRUZ - Salvador, BA \\ ${ }^{5}$ Embrapa Gado de Leite - Juiz de Fora, MG \\ ${ }^{6}$ Departamento de Veterinária - UFV - Viçosa, MG \\ ${ }^{7}$ Departamento de Informática - UFV - Viçosa, MG \\ ${ }^{8}$ Departamento de Zootecnia - UFLA - Lavras, MG
}

\begin{abstract}
RESUMO
Avaliou-se a resposta de cabras tratadas com r-bST no protocolo de sincronização de estro. Foram utilizadas 26 cabras Toggenburg, divididas em dois tratamentos: T1 $(\mathrm{n}=13)$, tratadas com quatro injeções de $250 \mathrm{mg}$ de $\mathrm{r}-$ bST, a intervalos de 14 dias, e T2 (n=13), tratadas com solução salina (controle). Na semana seguinte à última injeção da r-bST, colocou-se o dispositivo intravaginal com progesterona (dia 0), previamente utilizado por cinco dias, e injetou-se $\mathrm{PGF}_{2 \alpha}(22,5 \mu \mathrm{g})$ nos animais dos dois tratamentos, e o dispositivo foi retirado no dia 6. Todas as fêmeas em estro foram submetidas à monta natural. A porcentagem de animais em estro e a taxa de gestação foram 76,9 e 70,0 e 84,6 e 72,7\%, no T1 e T2, respectivamente. Não houve diferença $(P>0,05)$ na duração do estro, no intervalo tratamento-início do estro, no número de ovulações, nos intervalos: início e final do estro à ovulação e retirada do dispositivo à ovulação entre os animais dos dois tratamentos. $\mathrm{O}$ diâmetro médio dos folículos ovulatórios das fêmeas não diferiu $(\mathrm{P}>0,05)$. Durante a permanência do dispositivo, as concentrações séricas de progesterona apresentaram valores semelhantes $(\mathrm{P}>0,05)$ entre as cabras de T1 e T2. A r-bST não afetou a sincronização de estro.
\end{abstract}

Palavras-chave: caprino, dispositivo intravaginal, estro, taxa de gestação

\begin{abstract}
The response of goats treated with $r$-bST in the estrous synchronization protocol was evaluated. Twenty-six Toggenburg females were divided in two treatments: $T 1(n=13)$ treated with four injections of $250 \mathrm{mg} r-b S T$, at 14 days intervals, and $T 2(n=13)$ treated with saline solution (control). The intravaginal device previously used by five days was inserted (day 0) one week after the last injection of $r$-bST and $P G F_{2 \alpha}(22.5 \mu \mathrm{g})$ was injected in the animals of both treatments. The device was removed on day 6. All the females in estrus were bred by fertile bucks. The percentage of animals in estrus and the pregnancy rate were: 76.9 and 70 , and 84.6 and $72.7 \%$ for goats in $T 1$ and T2, respectively. The estrous cycle length; the interval from treatment to the onset of estrus; the ovulation number; and the intervals from the onset of estrus to ovulation, end of estrus to ovulation, and from device removal to ovulation were not affected by $r$-bST injection. The $r$-bST did not affect the diameter of the ovulatory follicles $(P>0.05)$. Progesterone concentration showed similar values $(P>0.05)$ among the goats of $T 1$ and $T 2$ during the treatment with device. The r-bST administration did not affect estrous synchronization.
\end{abstract}

Keywords: goat, intravaginal device, estrous, pregnancy rate

Recebido em 31 de agosto de 2006

Aceito em 17 de dezembro de 2007

E-mail: eamufv@yahoo.com.br

Apoio: FAPEMIG 


\section{INTRODUÇ̃̃O}

Métodos para sincronizar o estro têm sido desenvolvidos e utilizados na caprinocultura, visando facilitar e tornar mais eficiente o manejo reprodutivo (Fonseca, 2002; Maffili et al., 2003; Maffili et al., 2005; Leite et al., 2006).

A sincronização se baseia no encurtamento da fase luteal, pelo uso de agentes luteolíticos ou pelo prolongamento desta fase por meio de dispositivos de liberação lenta de progestágenos ou progesterona. Protocolos com períodos de utilização de dispositivos (CIDR ou esponja) inferiores a nove dias têm reportado sucesso (Maffili et al, 2003; Fonseca, 2005; Maffili et al., 2005). A associação de dispositivos intravaginais, utilizados por curto período, aos agentes luteolíticos como prostaglandinas, possibilita alta taxa de sincronização de estro $(>90 \%)$ em caprinos (Rubianes e Menchaca, 2003).

A somatotropina (ST), também conhecida como hormônio do crescimento $(\mathrm{GH})$, é uma proteína produzida pela hipófise anterior. Em bovinos, a somatotropina possui efeitos diretos e indiretos sobre o desempenho reprodutivo, e o seu uso em vacas lactantes tem sido associado com decréscimo na resposta reprodutiva, por exemplo, redução na taxa de prenhez (Lucy, 2001).

A ação da ST na regulação do crescimento folicular é relatada por vários autores. Seus efeitos sobre as células ovarianas ocorrem por meio de receptores detectados em ovários bovinos (Lucy et al., 1993). Em ovelhas e cabras, o GH promoveu aumento no número de folículos de 2-3mm (Gong et al., 1996), porém Driancourt e Disenhaus (1997) não observaram efeito da somatotropina bovina (bST) sobre o desenvolvimento e a maturação folicular em cabras. Moraes et al. (2004) constataram maior número de folículos $\geq 3 \mathrm{~mm}$ em cabras tratadas com somatotropina bovina recombinante (rbST). A r-bST é uma versão sintética da bST, produto veterinário produzido por meio da biotecnologia, mas que apresenta ação semelhante à bST.

Todavia, a eficiência de protocolos de sincronização de estro em cabras de produção submetidas a aplicações periódicas de somatotropina carece de maiores informações.

O objetivo deste estudo foi de avaliar parâmetros reprodutivos de cabras Toggenburg lactantes, tratadas com somatotropina bovina recombinante, submetidas à sincronização de estro.

\section{MATERIAL E MÉTODOS}

O estudo foi conduzido de maio a julho de 2003 , numa região localizada a $21^{\circ} 35^{\prime} \mathrm{S}$ e $43^{\circ} 15^{\prime} \mathrm{W}$, a $435 \mathrm{~m}$ de altitude e clima Cwa, segundo a classificação de Köpen, com temperatura média anual de $21^{\circ} \mathrm{C}$ e precipitação pluviométrica média anual de $1581 \mathrm{~mm}^{3}$.

Foram utilizadas 26 cabras $(140 \pm 2,7$ dias de lactação) da raça Toggenburg, sendo 13 multíparas (M), com peso em média de $48,3 \pm 5,9 \mathrm{~kg}$ e escore da condição corporal (escala de 1 a 5) de $3,1 \pm 0,5$ e 13 primíparas (P), com peso em média de $40,8 \pm 5,9 \mathrm{~kg}$ e escore de $3,5 \pm 0,8$.

Os animais foram mantidos em confinamento, com água à vontade e dieta formulada para suprirem as exigências nutricionais de cabras no terço médio da lactação, segundo NRC (Nutrient..., 1981). O volumoso utilizado foi o capim-elefante picado, e o concentrado foi constituído por milho, farelo de soja, farelo de girassol e mistura mineral.

Os animais foram distribuídos aleatoriamente em dois tratamentos (T): no T1 (6M e 7P) as cabras pesavam em média $44,0 \pm 6,0 \mathrm{~kg}$, tinham condição corporal de $3,2 \pm 0,7$, e receberam quatro injeções de $250 \mathrm{mg}$ de $\mathrm{r}-\mathrm{bST}^{1}$, por via subcutânea, a intervalos de 14 dias, na prega cutânea lateral da raiz da cauda, alternando-se os lados esquerdo e direito, a cada injeção; no T2 (7M e 6P) as cabras pesavam em média $44,6 \pm 7,9 \mathrm{~kg}$, tinham condição corporal de $3,5 \pm 0,7$ e receberam injeções de solução salina (controle).

A sincronização do estro dos animais de T1 e T2 foi realizada na semana seguinte à última injeção da r-bST. Os animais foram sincronizados com o dispositivo intravaginal Controlled Internal Drug

${ }^{1}$ Lactotropin: 500mg de Sometribove - Elanco - São Paulo, Brasil. 
Release $\left(\mathrm{CIDR}^{\circledR 2}\right)$, previamente utilizado por cinco dias e tratados com 22,5 $\mu \mathrm{g}$ de prostaglandina sintética ${ }^{3}$, por via intramuscular, no dia da inserção do dispositivo (dia 0) conforme Maffili (2004). A prostaglandina foi utilizada como agentes luteolíticos, a fim de provocar a destruição de corpo lúteo presente. No sexto dia após o início da sincronização, os dispositivos foram retirados e, a partir daí, os animais foram monitorados quanto à manifestação de estro a cada seis horas.

A detecção de estro foi realizada com o auxílio de um macho reprodutor. Foi considerada em estro a fêmea que aceitasse a monta. Para a cobertura foram utilizados cinco machos, com fertilidade comprovada, por via de exame andrológico (Manual..., 1998) e histórico anterior de cobertura. A cobertura foi repetida 12 horas após, quando as fêmeas ainda permaneciam em estro.

Após o início do estro, iniciaram-se os exames ultra-sonográficos a cada seis horas, até 12 horas após a detecção da ovulação. As imagens ultrasonográficas dos ovários foram obtidas por via transretal, com o auxílio de ultra-som ${ }^{6}$ acoplado a transdutor linear de $5 \mathrm{MHz}$. Os procedimentos para localização dos ovários foram os mesmos preconizados por Ginther e Kot (1994). O diâmetro, a posição, as características das estruturas ovarianas, o momento do início do estro e a ovulação foram registrados em fichas individuais.

As coletas de sangue para as dosagens de progesterona tiveram início um dia antes da inserção do dispositivo (dia 0 ), no dia de sua retirada (dia 6) e no sétimo dia após a inserção do dispositivo (dia 7). As amostras de sangue foram coletadas em tubos vacuolizados de $10 \mathrm{ml}$, sem solução anticoagulante, por punção da veia jugular. As amostras foram centrifugadas a 1000 $\mathrm{x} \mathrm{g}$, por 15 minutos. Os soros obtidos foram acondicionados em tubetes plásticos e armazenados à temperatura de $-18^{\circ} \mathrm{C}$ até sua análise. A dosagem de progesterona foi realizada no setor de reprodução animal do Departamento de Zootecnia - UFV, por meio de

${ }^{2}$ Eazi-Breed CIDR ${ }^{\circledR}$, Pharmacia Saúde Animal do Brasil Ltda - São Paulo, Brasil.

${ }^{3}$ Ciosin - Cooper - São Paulo, Brasil.

${ }^{6}$ Aloka - modelo SSD-500 - Tokio, Japão radioimunoensaio (RIA) em fase sólida, com o emprego de kit comercial ${ }^{4}$.

O diagnóstico de gestação foi feito no $35^{\circ}$ dia após a cobertura, com o auxílio de ultra-som ${ }^{5}$ acoplado à probe de $5 \mathrm{MHz}$.

$\mathrm{Na}$ análise estatística utilizou-se o programa SAEG (Sistema..., 1997). Para verificar a normalidade e a homogeneidade das variáveis estudadas, empregaram-se os testes de Lilliefors e Cochran e Barttlet, respectivamente. Aplicouse a análise de variância para verificar diferenças entre as variáveis estudadas. Quando presentes, as diferenças foram testadas pelo teste de Tukey. As variáveis que não apresentavam normalidade ou homogeneidade, mesmo após a transformação logarítmica, foram submetidas à análise não paramétrica de Wilcoxon.

\section{RESULTADOS E DISCUSSÃO}

Em três cabras do T1 e em duas do T2 não houve resposta ao tratamento com o dispositivo. Tal fato se deve às concentrações de progesterona apresentados após a retirada do dispositivo $(3,47$ e 4,11ng/ml, respectivamente).

O número de cabras em que se apresentou estro e a taxa de gestação estão na Tab. 1. Não houve diferença da taxa de gestação entre os animais dos dois tratamentos. $\mathrm{O}$ baixo número de animais utilizado no experimento impossibilitou a análise pelo teste do qui-quadrado.

A taxa de ocorrência de estro e a taxa de gestação foram semelhantes às reportadas por Oliveira et al. (2001); Maffili (2004); Maffili et al. (2005) e superiores às encontradas por Motlomelo et al. (2002). McGrath et al. (1999) trabalharam com vacas no final da lactação e não observaram efeito na taxa de gestação entre os animais tratados e os controles. O mesmo resultado foi observado entre os tratamentos (Tab. 1). Observou-se que o tratamento com $r$ bST não provocou efeitos negativos sobre os parâmetros reprodutivos de cabras no terço médio da lactação, quando a produção de leite estava diminuindo.

${ }^{4}$ Coat-a-count progesterone -DPC - Diagnostic Products Co. - Los Angeles, EUA. 
Tabela 1. Número de animais em estro (NO), taxa de gestação (TG), intervalo da retirada do dispositivo e início do estro (IRDIE), duração do estro (DE), intervalo da retirada do dispositivo e final do estro (IRDFE) em cabras da raça Toggenburg, tratadas (T1) e não tratadas (T2) com r-bST, sincronizadas com dispositivo intravaginal com progesterona, previamente utilizado por cinco dias (média \pm desvio padrão)

\begin{tabular}{lccc}
\hline Variável & T1 & T2 & Total \\
\hline NO (\%) & $76,9(10 / 13)$ & $84,6(11 / 13)$ & $80,8 \%(21 / 26)$ \\
TG (\%) & $80,0(8 / 10)$ & $72,7(8 / 11)$ & $76,2(16 / 21)$ \\
IRDIE (horas) & $28,8 \pm 4,7 \mathrm{a}$ & $31,6 \pm 7,6 \mathrm{a}$ & $30,3 \pm 6,4$ \\
DE (horas) & $42,0 \pm 14,4 \mathrm{~A}$ & $30,5 \pm 15,3 \mathrm{~A}$ & $36,0 \pm 15,6$ \\
IRDFE (horas) & $70,8 \pm 14,9 \mathrm{~A}$ & $62,2 \pm 18,0 \mathrm{~A}$ & $66,3 \pm 16,8$ \\
\hline
\end{tabular}

Médias seguidas por letras minúsculas iguais na linha não diferem entre si (teste de Wilcoxon, $\mathrm{P}>0,05$ ).

Médias seguidas por letras maiúsculas iguais na linha não diferem entre si (teste de Tukey, $\mathrm{P}>0,05$ ).

Não houve diferença $(\mathrm{P}>0,05)$ quanto aos intervalos de retirada do dispositivo em relação ao início e ao final do estro entre as cabras dos dois tratamentos (Tab. 1). Os valores médios encontrados foram semelhantes aos relatados por Motlomelo et al. (2002) e Maffili (2004) e diferentes dos observados por Brozos et al. (1999), que trabalharam com sincronização de estro com esponja intravaginal, em ovelhas. Conforme constatado por Maffili et al. (2003), os animais sincronizados com o CIDR apresentaram início do estro mais rápido que os sincronizados com esponjas intravaginais impregnadas com acetato de medroxiprogesterona. Os resultados encontrados neste estudo foram semelhantes aos de Motlomelo et al. (2002), que compararam diferentes progestágenos na sincronização de cabras durante a estação natural. Neste estudo não foi verificada correlação entre o intervalo da retirada do dispositivo e o início e a duração do estro.

$\mathrm{O}$ número de ovulações não diferiu $(\mathrm{P}>0,05)$ entre os animais dos dois tratamentos, (Tab. 2), apesar de a r-bST (via IGF-1) aumentar o efeito estimulatório do FSH sobre a esteroidogênese das células da granulosa e induzir o aumento de receptores para o LH (Kirkwood et al., 1988). Esperava-se com esse efeito que o número de ovulações fosse diferente nos animais tratados com a r-bST. Godfrey et al. (1997) observaram resultados semelhantes ao sincronizar o estro de ovelhas nos trópicos.

Tabela 2. Número de ovulações (NO), intervalo início do estro à ovulação (IIEO), intervalo do final do estro à ovulação (IFEO), intervalo da retirada do dispositivo à ovulação (IRDO), diâmetro médio dos folículos ovulatórios(DMFO), ovário em que ocorreu a ovulação (OD e OE) e taxa de crescimento (TC) dos folículos ovulatórios, em cabras da raça Toggenburg tratadas (T1) e não tratadas com r-bST (T2), sincronizadas com o dispositivo intravaginal que continha progesterona e utilizado previamente por cinco dias (média \pm desvio padrão)

\begin{tabular}{lccc}
\hline Variável & r-bST & Controle & Média Geral \\
\hline NO & $1,7 \pm 0,7 \mathrm{a}$ & $1,4 \pm 0,7 \mathrm{a}$ & $1,6 \pm 0,7$ \\
IIEO (horas) & $24,0 \pm 8,9 \mathrm{a}$ & $24,5 \pm 8,7 \mathrm{a}$ & $24,3 \pm 8,6$ \\
IFEO (horas) & $-18,0 \pm 15,0 \mathrm{~A}$ & $-6,0 \pm 11,4 \mathrm{~A}$ & $-11,7 \pm 14,2$ \\
IRDO (horas) & $52,8 \pm 9,3 \mathrm{a}$ & $56,2 \pm 12,4 \mathrm{a}$ & $54,6 \pm 10,9$ \\
DMFO (cm) & $0,9 \pm 0,1 \mathrm{~A}$ & $0,9 \pm 0,2 \mathrm{~A}$ & $0,9 \pm 0,15$ \\
TC (mm/hora) & $0,61 \pm 0,01 \mathrm{~A}$ & $0,58 \pm 0,01 \mathrm{~A}$ & $0,60 \pm 0,02$ \\
& $7(46,7)$ & $7(58,3)$ & $14(51,8)$ \\
OD (\%) & $8(53,3)$ & $5(41,7)$ & $13(48,2)$ \\
OE (\%) & &
\end{tabular}

Médias seguidas por letras minúsculas iguais na linha não diferem entre si (teste de Wilcoxon, $\mathrm{P}>0,05$ ).

Médias seguidas por letras maiúsculas iguais na linha não diferem entre si (teste de Tukey, $\mathrm{P}>0,05$ ).

Não houve efeito $(\mathrm{P}>0,05)$ do tratamento com $\mathrm{r}$ bST sobre os intervalos de início do estro à ovulação e de retirada do dispositivo à ovulação.
Os intervalos mínimos e máximos observados entre o início do estro e a ovulação foram de 12 e 42 horas no T1 e 18 e 48 horas no T2, 
respectivamente. Prasad et al. (1979) observaram ovulações entre 10 e 40 horas após o início do estro. Não houve correlação entre o intervalo de retirada do dispositivo e início do estro e a ovulação. Quanto ao intervalo do final do estro à ovulação, os animais tratados com r-bST apresentaram intervalo maior $(\mathrm{P}<0,10)$ que os controles (Tab. 2).

O diâmetro médio do folículo ovulatório e a taxa de crescimento dos folículos ovulatórios não foram influenciados $(\mathrm{P}>0,05)$ pelo tratamento com r-bST (Tab. 2). Segundo Tanner e Hauser, (1989), o r-bST age sobre o ovário estimulando a síntese do fator de crescimento semelhante à insulina 1 (IGF-1) e controla, especialmente, a função do corpo lúteo (Lucy et al., 1993) e das células da granulosa (Lobie et al., 1990). Os folículos apresentam menores quantidades de receptores para somatotropina, pois a presença destes demonstra sua efetividade, alterando assim sua função (Lucy, 2000). Foi constatado que a somatotropina pode afetar a dinâmica folicular, como a quantidade de folículos em emergência, porém sem causar efeitos em outras variáveis (Lucy, 2000; Moraes et al., 2004; Amorim et al., 2007). A taxa de crescimento folicular só foi avaliada depois do início do estro, período que corresponde à fase sem o efeito negativo da progesterona sobre o desenvolvimento folicular.

Não houve diferença de atividade $(\mathrm{P}>0,05)$ entre os ovários direito e esquerdo dos animais dos dois tratamentos (Tab. 2), resultado que corrobora os de Romano e Abella (1997) que trabalharam com cabras da raça Nubiana. Camp et al. (1983), entretanto, observaram que a atividade do ovário direito foi maior que do esquerdo.

A concentração sérica de progesterona não diferiu $(\mathrm{P}>0,05)$ entre os animais tratados (T1) ou não (T2) com r-bST (Fig. 1). Amorim et al. (2007), também, não observou diferença na concentração sérica de progesterona entre os animais tratados e os não tratados com r-bST. No dia 0 da permanência do dispositivo intravaginal as médias foram: $\mathrm{T} 1=9,72 \pm 2,55$ e $\mathrm{T} 2=$ $12,23 \pm 3,66$; no sexto dia foram: $\mathrm{T} 1=2,36 \pm 0,55 \mathrm{e}$ $\mathrm{T} 2=1,85 \pm 0,51)$. No sétimo dia, um dia após a retirada do dispositivo, em todos os animais (T1+T2), a concentração sérica de progesterona caiu para valores inferiores a $1 \mathrm{ng} / \mathrm{ml}$, o que demonstra a rápida taxa de metabolização pelo fígado. As concentrações de progesterona no dia da remoção e no dia seguinte à retirada do CIDR foram semelhantes às encontradas por Maffili (2004), que também sincronizou o estro de cabras da raça Toggenburg com CIDR reutilizado pela segunda vez.

A taxa de parto, o período de gestação e o número médio de crias por parto não foram influenciados $(\mathrm{P}>0,05)$ pela r-bST (Tab. 3). O período médio de gestação e o número médio de cabritos nascidos foram semelhantes aos relatados para a espécie caprina (Gordon, 1997).

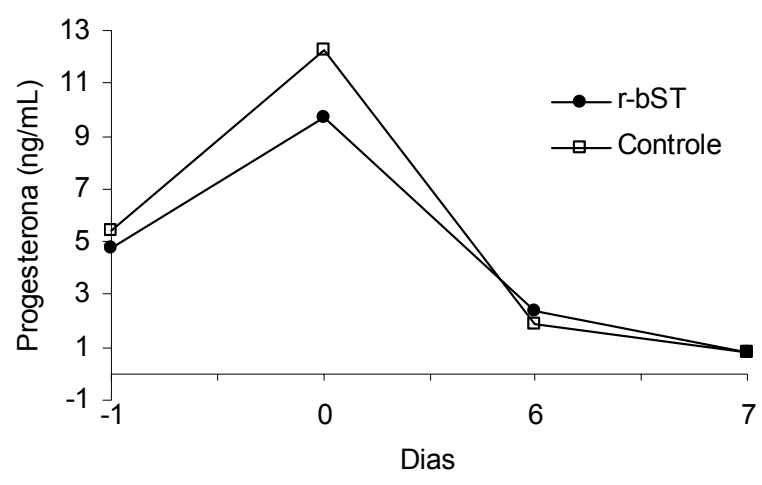

Figura 1. Concentração sérica de progesterona de cabras da raça Toggenburg tratadas com r-bST e não tratadas (controle), sincronizadas com dispositivo intravaginal que continha progesterona, previamente utilizado por cinco dias. Dia $0=$ colocação do dispositivo reutilizado $+\mathrm{PGF}_{2 \alpha}$; dia $6=$ retirada do dispositivo. 
Tabela 3. Taxa de parto (TP), duração da gestação (DG) e número de crias nascidas (NCN) em cabras da raça Toggenburg, tratadas (T1) e não tratadas com r-bST (T2), sincronizadas com o dispositivo intravaginal com progesterona, previamente utilizado por cinco dias (média \pm desvio padrão)

\begin{tabular}{lccc} 
Variável & T1 & T2 & Total \\
\hline TP $(\%)$ & $50(5 / 10)$ & $63,6(7 / 11)$ & $52,4(12 / 21)$ \\
DG (dias) & $149 \pm 1,22(5) \mathrm{a}$ & $148,3 \pm 2,43(7) \mathrm{a}$ & $148,6 \pm 1,97$ \\
NCN & $1,20 \pm 0,45 \mathrm{a}$ & $1,57 \pm 0,53 \mathrm{a}$ & $1,42 \pm 0,5$ \\
\hline
\end{tabular}

Médias seguidas por letras iguais na linha não diferem entre si (teste de Tukey, $\mathrm{P}>0,05$ ).

Não foi verificada correlação entre o número de ovulações e o número de crias nascidas $(\mathrm{P}>0,05)$.

\section{CONCLUSÕES}

Pode-se utilizar o CIDR por até duas vezes, sem perda da eficiência reprodutiva. Sua reutilização, contudo, neste estudo esteve condicionado a sua utilização prévia por somente cinco dias.

\section{REFERÊNCIAS BIBLIOGRÁFICAS}

AMORIM, E.A.M.; TORRES, C.A.A.; FONSECA, J.F. et al. Dinâmica folicular em cabras da raça Toggenburg em lactação tratadas ou não com somatotropina recombinante. Arq. Bras. Med. Vet. Zootec., v. 59, p.1500-1508, 2007.

BROZOS, C.N.; SARATSIS, P.H.; BOSCOS, C. et al. Effect of bovine somatotropin (bST) administration on reproduction, progesterone concentration during lactation and $\mathrm{LH}$ secretion during estrus, in dairy ewes. Anim. Reprod. Sci., v.56, p.177-187, 1999.

CAMP, J.C.; WILDT, D.E.; HOWARD, P.K. et al. Ovarian activity during normal and abnormal length estrous cycles in the goat. Biol. Reprod., v.28, p.673-681, 1983.

DRIANCOURT, M.A.; DISENHAUS, C. Lack of effects of growth hormone administration on function of lactating goats. Anim. Reprod. Sci., v.46, p.123-132, 1997.

FONSECA, J.F.; BRUSCHI, J.H.; SANTOS, A.F.A. et al. Sincronização de estro em cabras Toggenburg durante a estação de acasalamento. In: REUNIAO ANUAL DA SOCIEDADE BRASILEIRA DE ZOOTECNIA, 42., 2005, Goiânia: Anais... Goiânia, 2005 (CD-ROOM).

FONSECA, J.F. Controle e perfil hormonal do ciclo estral e performance reprodutiva de cabras alpina e saanen. 2002. 107f. Tese (Doutorado) Universidade Federal de Viçosa, Viçosa.

GINTHER, O.J.; KOT, K. Follicular dynamics during the ovulatory season in goats. Theriogenology, v.42, p.987-1001, 1994.

GODFREY, R.W.; GRAY, M.L.; COLLINS, J.R. A comparison of two methods of oestrus synchronization of hair sheep in the tropics. Anim. Reprod. Sci., v.47, p.99-106, 1997.

GONG, J.G.; CAMPBELL, B.K.; BRAMDLEY, $\mathrm{T}$. et al. Treatment with recombinant bovine somatotropina enhances ovarian follicle development and increases the secretion of insulin like growth factor I by ovarian follicles in ewes. Anim. Reprod. Sci., v.41, p.13-26, 1996.

GORDON, I. (Ed). Controlled reproduction in sheep and goats. Cambridge: University Press, 1997. p.62.

KIRKWOOD, R.N.; TCHACKER, P.A.; GOONERATNE, A.D. et al. The influence of exogenous growth hormone on ovulation rate in gilts. Can. J. Anim. Sci., v.68, p.1097-1103, 1988.

LEITE, P.A.G.; CARVALHO, G.R.; RODRIGUES, M.T. et al. Indução da ovulação em cabras, fora da estação reprodutiva, com LH e GnRH e com estro induzidos por progestágenos. Arq. Bras. Med. Vet. Zootec., v.58, p.360-366, 2006.

LOBIE, P.E.; BREIPOHL, W.; ARAGON, J.G. et al. Cellular localization of the growth hormonal receptor/binding protein in the male and female reproductive systems. Endocrinology, v.126, p.2214-2221, 1990.

LUCY, M.C. Regulation of ovarian follicular growth by somatotropina and insulin-like growth factors in cattle. J. Dairy Sci., v.83, p.1635-1647, 2000.

LUCY, M.C. Expectativas de índices reprodutivos em vacas leiteiras tratadas com 
somatotropina bovina. In: CURSO DE NOVOS ENFOQUES NA PRODUÇÃO E REPRODUÇÃO DE BOVINOS, 5., 2001. Uberlândia: [Anais]... Uberlândia: UFU, 2001, p. 47-55.

LUCY, M.C.; COLIIER, R.J.; KITCHELL, M.L. et al. Immunohistochemical and nucleic acid analyses of somatotropin receptor populations in the bovine ovary. Biol. Reprod., v.48, p.12191227, 1993.

MAFFILI, V.V. Caracterização de protocolos visando à máxima eficiência reprodutiva em caprinos. 2004. 118f. Tese (Doutorado) Universidade Federal de Viçosa, Viçosa.

MAFFILI, V.V.; FONSECA, J.F.; PONTES, R.A M. et al. Comparação entre controlled internal drug release (CIDR ) utilizado uma, duas ou três vezes em programas de sincronização de estro em cabras da raça toggenburg. Arq. Cien. Vet. Zool. Unipar, v.31, p.244, 2003.

MAFFILI, V.V.; TORRES, C.C.A.; FONSECA, J.F. et al. Sincronização de estro em cabras da raça Saanen com esponja intravaginal e CIDR-G. Arq. Bras. Med. Vet. Zootec., v.57, p.591-598, 2005.

MANUAL para exame andrológico e avaliação de sêmen animal. 2.ed. Belo Horizonte: CBRA, 1998. 49p

McGRATH M.F.; BETTIS, S.E.; BILBY, C.R. et al. Effect of delayed breeding on reproduction, milk yield and lactation persistency in cows supplemented with POSILAC®. J. Dairy Sci., v.82. suppl.1, p.36, 1999. (abstract)

MORAES, E.A.; TORRES, C.A.A.; AMORIM, L.S. et al. Parâmetros produtivos e reprodutivos de cabras da raça Toggenburg em lactação tratadas com somatotropina bovina recombinante. REUNIÃO ANUAL DA SOCIEDADE BRASILEIRA DE ZOOTECNIA, 41., 2004, Campo Grande. Anais... Campo Grande, 2004 (CD-ROOM).

MOTLOMELO, K.C.; GREYLING, J.P.C.; SCHWALBACH, L.M.J. Synchronization of oestrus in goats: the use of different progestagen treatments. Small Rumin. Res., v.45, p.45-49, 2002.

NUTRIENT requirements of goats. Washington: National Academy of Sciences, 1981.

OLIVEIRA, M.A. L.; GUIDO, S.I.; LIMA. P.F. Comparison of different protocols used to induce and synchronize estrous cycle of Saanen goats. Small Rum. Res., v.40, p.149-153, 2001.

PRASAD, S.P.A note on the occurrence of short oestrus cycles and possible association of ovarian activity in Barbari nannies. Ind. J. Anim. Sci., v.49, p.854-856, 1979.

ROMANO, J.E.; ABELLA, D.F. Effect of service on duration of oestrus and ovulation in dairy goats. Anim. Reprod. Sci., v.47, p.107-112, 1997.

RUBIANES, E., MENCHADA, A. The pattern and manipulation of ovarian follicular growth in goats. Anim. Reprod. Sci., v.78, p.271-287, 2003.

SISTEMA de análises estatísticas - SAEG. Versão 8.0.Viçosa: UFV, 1997. 150p.

TANNER, J.W.; HAUSER, S.D. Molecular evidence for the presence of the somatotropina receptor in the bovine ovary. J. Anim. Sci., v.67, suppl.1, p.413, 1989. (abstract). 